\title{
Small temporal differences in water uptake among varieties of pearl millet (Pennisetum glaucum (L.) R. Br.) are critical for grain yield under terminal drought
}

\author{
Vincent Vadez • Jana Kholová • Rattan S. Yadav • \\ Charles Tom Hash
}

Received: 28 May 2012 / Accepted: 24 March 2013 / Published online: 10 April 2013

(C) The Author(s) 2013. This article is published with open access at Springerlink.com

\begin{abstract}
Background and aim Intuitively, access to water from the soil at key phenological stages is important for adaptation to drought. This study aimed to assess the temporal pattern of water extraction under terminal drought stress.

Methods Pearl millet genotypes with varying levels of terminal drought tolerance were grown in a lysimetric system with a soil volume and plant spacing similar to field conditions. Water extraction was monitored until maturity under differing water regimes.

Results The yield did not differ among genotypes under well-watered (WW) conditions, and the water extraction profile of WW plants was similar across all genotypes. In contrast, the yield of sensitive genotypes was 30-100\% lower than that of tolerant lines under water stress (WS). The total volumes of water extracted
\end{abstract}

Responsible Editor: Martin Weih.

Electronic supplementary material The online version of this article (doi:10.1007/s11104-013-1706-0) contains

supplementary material, which is available to authorized users.

V. Vadez $(\square) \cdot J$. Kholová $\cdot$ C. T. Hash

International Crops Research Institute

for the Semi-Arid Tropics,

Patancheru 502 324, Andhra Pradesh, India

e-mail: v.vadez@cgiar.org

\section{R. S. Yadav}

Institute of Biological, Environmental and Rural Sciences, Gogerddan Aberystwyth University,

Aberystwyth SY23 3EB, UK by tolerant and sensitive genotypes were similar under WS; however, tolerant genotypes extracted less water prior to anthesis, and more water after anthesis. Grain yield was positively related to the amount of water extracted during week three after panicle emergence. Increased water extraction after anthesis benefitted the tillers more than the main culm and was correlated with higher staygreen scores.

Conclusion Increased water uptake after anthesis, which results from earlier water conservation during pre-anthesis, increases yield under terminal drought in pearl millet.

Keywords Roots · Water extraction - Lysimeter . Drought QTL · Water conservation

\section{Introduction}

Drought is the most important abiotic stress that limits plant productivity and will only worsen in the future when constraints on water resources increase. Plant coping strategies under water deficit are limited and revolve around the need to use water in an efficient way, ensure that water is available for the grain filling period, and maximise water capture from the soil profile.

In previous reports, a major terminal drought tolerance quantitative trait locus (QTL) was identified and confirmed in two different genetic backgrounds (Yadav et al. 2002, 2004; Serraj et al. 2005). This major QTL was identified based on yield differences under terminal 
drought, which was applied by stopping irrigation either at panicle emergence or at flowering, in repeated field trials. The phenotype used to detect this large QTL was the panicle harvest index, i.e., the ratio of the grain weight to the panicle weight, which reflects the success of seed set and seed fill. A higher grain yield under terminal drought was then a consequence of differences in seed number and size (Bidinger et al. 1987). However, this QTL spans a genomic region of approximately $30 \mathrm{cM}$, which is too large to be routinely used in an applied breeding program, and the underlying mechanisms of the QTL are still unclear. Therefore, dissecting this QTL into more easily transferable components is necessary for breeding. Obtaining an understanding of the mechanisms leading to improved seed fill and seed set that are conferred by this QTL is a critical first step.

In recent work, near isogenic lines (NILs) introgressed with this terminal drought tolerance QTL (NIL-QTLs) had a lower canopy conductance (Kholová et al. 2010a), which was also sensitive to a high vapour pressure deficit (Kholová et al. 2010b). These traits contribute to water conservation and cause genotypes to use the soil water at a slower pace, hence leaving water available for the grain filling period. Similar water conservation traits also appear to operate in terminal drought tolerant chickpeas (Zaman-Allah et al. 2011a), and indeed, these traits altered the pattern of water extraction in a way that left more water available for the grain filling period (ZamanAllah et al. 2011b). In wheat, "water conservative" lines with low $\Delta^{13} \mathrm{C}$ had an advantage when they were grown on stored soil moisture or in areas with limited rainfall (Condon and Richards 1993; Condon et al. 2002, 2004; Rebetzke et al. 2002).

Differences in root morphology may also be responsible for differences in terminal drought tolerance among different crops (Price and Tomos 1997; Tuberosa et al. 2002; Kashiwagi et al. 2006; Gaur et al. 2008). Grain yield under stress is indeed influenced by deep rooting in crops such as chickpea (Kashiwagi et al. 2006) and wheat (Ehdaie et al. 2012). In rice plants, lateral root branching was promoted under mild water stress and contributed to root plasticity and genotype performance (Kano et al. 2011). However, these preliminary studies relied on structural assessments of roots, which are destructive measurements. Measuring water uptake in vivo over the entire life of the crop would provide better information regarding the functional role of the root in water extraction compared with a one-time root morphology assessment (Vadez et al. 2007, 2008). Indeed, effective use of water, which partially involves maximising plant water capture from the soil profile, is critical for drought adaptation (Blum 2009). For example, Manshadi et al. (2010) showed that a narrower root architecture in the wheat genotype SeriM82 increased water extraction and yield in water-limited environments. Drought-adapted water conserving wheat genotypes exhibited less root growth and water extraction; however, this was compensated for by a higher transpiration efficiency (Mori and Inagaki 2012). In maize, genetic variation in root architecture was also noted, although deeper rooting was related to lower water use efficiency (Hund et al. 2009). Thus, while roots are likely to play a role in the drought adaptation of different crops, the extent to which they contribute and their interactions with other traits that contribute to plant water use remain unclear. Additionally, it is not known whether this terminal drought tolerance QTL in pearl millet contributes to an increase in water uptake.

In this work, we first wanted to understand whether contrasting genotypes differ in the total amount of water extracted from the soil profile, and second, we wanted to explore whether the timing of water uptake is an important factor. Our first focus follows recent work in sorghum showing differences in total water extraction under terminal drought among germplasm entries (Vadez et al. 2011a) and among staygreen QTLintrogressed sorghum lines (Vadez et al. 2011b). Our second focus follows recent work in chickpea, in which greater water extraction during the grain filling period (rather than total water uptake) discriminated terminal drought-tolerant from terminal drought-sensitive lines (Zaman-Allah et al. 2011b). Here, the pattern of water use was assessed in NIL-QTLs to explore possible variations leading to differences in grain yield. This work was done in a lysimetric system, i.e., a set of long, large tubes that mimic field conditions with regard to soil profile, water availability and aerial plant spacing (Vadez et al. 2008). Yield evaluations in this system agree with field assessments (Zaman-Allah et al. 2011b; Vadez et al. 2011a, b) and are combined to achieve a precise assessment of the components of a water-based framework $(\mathrm{Y}=\mathrm{WU} \times \mathrm{TE} \times \mathrm{HI})($ Passioura 1977), where Y, WU, TE, and HI represent yield, water uptake, transpiration efficiency and harvest index, respectively. Few reports have assessed plant water use starting from an early vegetative stage and continuing until maturity using large containers (Payne et al. 1991, 
1992). Additionally, the staygreen phenotype, which is hypothesised to be a consequence of increased water extraction during grain filling, was measured here as an attempt to transfer this knowledge to field applications. Therefore, the current approach creates a framework in which several traits that potentially contribute to drought adaptation are combined, using NIL-QTLs, in an attempt to more effectively bridge physiology, genetics, and breeding (Cattivelli et al. 2008).

The main objective of this work was to assess the temporal pattern of water extraction in pearl millet and test possible relationships with yield differences under terminal drought. The specific objectives were to (i) assess seed yield differences under terminal drought and fully irrigated conditions, (ii) compare the timing of water extraction and the total amount of water extracted by these lines, and (iii) assess how putative differences in the temporal water extraction patterns correlate with seed yield and particularly with tiller seed yield, seed size, and staygreen scores. The work was performed using contrasting pearl millet test-cross hybrids, including NILs for a terminal drought tolerance QTL, in a lysimetric system that allows plant water extraction to be monitored.

\section{Materials and methods}

\section{Plant material}

Two pearl millet (Pennisetum glaucum [L.] R. Br.) genotypes with contrasting tolerance to drought stress (PRLT 2/89-33 [tolerant] and H 77/833-2 [sensitive])and six QTL-introgression lines (ICMH 01029, ICMH 01031, ICMH 02040, ICMH 01046, ICMH 02042, ICMH 02044) were tested (details on their development are available in Kholová et al. 2010a). The work was performed using test-cross hybrids of these genotypes, which were developed by crossing the inbred parental lines and QTL-NILs to the male-sterile line tester 843A (Yadav et al. 2004). ICMH 01029, ICMH 02040, ICMH 01046, and ICMH 01031 were selected for their superior combined seed yield across a range of terminal drought environments (Serraj et al. 2005). ICMH 01029, ICMH 01031, ICMH 02042, and ICMH 02044 also exhibited contrasting water conservation traits at various vegetative stages under non-stress conditions (Kholová et al. 2010a, b).
Growth conditions in the lysimeters and water in the soil profile

Plants were grown outdoors in lysimeters, i.e., PVC tubes $25 \mathrm{~cm}$ in diameter and $2.0 \mathrm{~m}$ long that were filled with a sandy clay loam Alfisol at a bulk density of approximately $1.35 \mathrm{~g} \mathrm{~cm}^{-3}$, which is a standard value for Alfisols. The Alfisol was collected from the ICRISAT farm and sieved to particles smaller than 1 $\mathrm{cm}$. Although at first filling the original structure of the soil was disturbed, a normal soil structure was likely to have been established over the lifetimes of the different crops that preceded this one. Details regarding soil filling and fertilisation are described in an earlier paper (Vadez et al. 2011a). Plant spacing and soil volume available for water extraction in the lysimetric system were similar to those in field conditions; however, the system did not reproduce root-to-root competition.

The cylinders could be lifted and weighed with a block-chained pulley and an S-type load cell with a 200-kg capacity (Mettler-Toledo, Geneva, Switzerland) and an accuracy of $20 \mathrm{~g}$. The lysimeters were separated from one another by a distance of approximately $5 \mathrm{~cm}$; thus, the plant density was approximately 10 plants $\mathrm{m}^{-2}$, which is similar to typical pearl millet field plantings at ICRISAT. This allowed an accurate assessment of the water extraction pattern of a crop cultivated under conditions similar to those in the field.

Prior to their use with the pearl millet crop, the lysimeters were used to grow a crop of foxtail millet followed by a crop of sorghum. While harvesting the previous crops, only the main root stock of the plants was removed, and the soil was tilled superficially with sickles. Therefore, the soil profile in which the pearl millet was cultivated was mostly undisturbed during the previous croppings except for minimal surface tillage.

Water extraction measurements and treatments used

Seeds were sown in four hills in each cylinder on February 7th, 2009. During the cropping period, the maximum and minimum temperatures ranged from 29.4 $40.7{ }^{\circ} \mathrm{C}$ to $15-27.5^{\circ} \mathrm{C}$, respectively, and the maximum and minimum relative humidity ranged from 50 91 to $14-52 \%$, respectively. The average vapour pressure deficits during the cropping and transpiration monitoring 
periods were $2.55 \mathrm{kPa}$ and $2.69 \mathrm{kPa}$, respectively. The plants were thinned to two seedlings per cylinder at 14 days after sowing (DAS) and later thinned to one plant per cylinder at 21 DAS. The crop was top dressed with $1.38 \mathrm{~g} \mathrm{~N}$ plant $^{-1}$ (as urea) at $28 \mathrm{DAS}$. All the plants were fully irrigated until 28 DAS. Each cylinder received 500 $\mathrm{mL}$ of water twice a week until $14 \mathrm{DAS}$ and $500 \mathrm{~mL}$ on alternate days thereafter until 28 DAS. At 26 DAS, the cylinders were covered with a 2-cm layer of low-density polyethylene beads to prevent soil evaporation. No correction was made for biomass increase between weighings as this was negligible compared to plant water use. Weighings were performed at 29, 34, 39, 46, 54, 60, and 77 DAS.

Three water treatments were used: a well-watered control (WW), which was watered each week, an early water stress (ES) treatment imposed by applying a final irrigation of $2 \mathrm{~L} \mathrm{plant}^{-1}$ at 34 DAS (at panicle emergence), and a late water stress (LS) treatment imposed by applying a final irrigation of $2 \mathrm{~L}_{\text {plant }}{ }^{-1}$ at 41 DAS (2 days after the mean flowering date). A randomised block design was used with treatment as the main factor and genotype as the sub-factor, which was randomised within each main factor. Wellwatered plants were watered every week, and rewatering was performed up to $2 \mathrm{~kg}$ below the field capacity weight (obtained on 29 DAS) to avoid water drainage. At 68 DAS, the WW plants received an additional irrigation with the same amount of water applied after the 60 DAS weighing.

Flowering time (d) was recorded for each individual plant. The staygreen phenotype was scored 3 weeks after panicle emergence in the LS treatment group using a 3-point scale (1, all leaves are wilted or showing senescence; 2 , some of the leaves are wilting or showing senescence; 3 , most/all leaves are green and turgid). Water extraction to support transpiration was calculated from cylinder weight differences and water additions. Six (WW and LS) and five (ES) transpiration values were obtained. Pre-anthesis water extraction was calculated as the sum of the first two transpiration values (until 39 DAS). Post-anthesis water extraction was calculated as the sum of the transpiration values after 39 DAS. At harvest, the main culm and tillers were harvested separately, and for each part, the masses of leaves and stems including sheaths, panicles, and grains were recorded after drying for 3 days in a forced air oven set at $70{ }^{\circ} \mathrm{C}$. The number of grains per plant and the 100 -grain weight were then determined without separating the main culm from the tillers. The panicle harvest index (PNHI) was calculated by dividing the grain yield by the total panicle biomass. Transpiration efficiency (TE) was calculated by subtracting the biomass at 29 DAS from the total aboveground biomass and dividing the result by the total amount of transpiration from 29 DAS until maturity. The biomass at 29 DAS was measured using an extra set of plants grown under WW conditions and ranged from 17 to $23 \mathrm{~g}$ across the genotypes. Roots were not extracted in this trial; thus, the TE assessment was based only on shoot biomass and was slightly underestimated. In earlier studies, we hypothesised that omitting the roots was not likely to alter the genotypic ranking (Vadez et al. 2011a, b).

Data management and statistical analysis

The crop preceding pearl millet in the lysimeters (Vadez et al. 2011a, b) underwent different watering regimes. Watering prior to sowing the pearl millet crop did not restore a full soil profile in all cylinders. Therefore, the soil moisture content differed significantly among the cylinders when pearl millet was initially planted. The cylinder weight ranged from 156 to $164 \mathrm{~kg}$, whereas tubes at field capacity normally weigh between 163 and $165 \mathrm{~kg}$. This caused significant linear relationships between the total seed yield and the initial cylinder weight in each of the two WS treatments $\left(\mathrm{R}^{2}=0.21\right.$ in the $\mathrm{LS} ; \mathrm{R}^{2}=0.48$ in the $\left.\mathrm{ES}\right)$. However, in each WS treatment, linear regressions were run on separate groups of lysimeters with cylinder weights either below or above a median weight (159.4 $\mathrm{kg}$ in LS and $160.5 \mathrm{~kg}$ in ES). These relationships were non-significant in the LS group $\left(\mathrm{R}^{2}=0.04\right.$ and $\mathrm{R}^{2}=0.04$ for cylinders below and above the median weight, respectively), and were significant but relatively weak in the ES group $\left(\mathrm{R}^{2}=0.07\right.$ and $\mathrm{R}^{2}=$ 0.12 for cylinders below and above the median weight, respectively). Therefore, the cylinders were separated into those with an unfilled profile (weight below the median) and those with a full profile (weight above the median), and four WS treatments were considered in the data analysis: ES with either a full profile (FP) or an unfilled profile (UP) and LS with either an FP or a UP. In fact, what appeared initially to be an experimental caveat provided us with an interesting opportunity to test crop responses under a wide range of stress conditions. 
For the statistical analysis, regressions were analysed using Pearson correlation coefficients. One-way ANOVAs were performed to assess genotypic effects, which were fixed effects, within each of the watering regimes (including the WW treatment). Subsequently, a two-way ANOVA was used to assess treatment (T), genotypic (G) and genotype-by-treatment interactions (GxT) considering each of the four WS treatments individually and excluding the WW treatment. To perform the multi-linear regression analysis, we used the multilinear additive model in STATA (Stata Corp., College Station, TX, USA) with yield as an additive function of water uptake (WU), transpiration efficiency (TE), harvest index (HI), and WU at different time points during the crop cycle. A similar model was used in which the PNHI was considered an additive function of WU at different time points during the crop cycle.

\section{Results}

Agronomic traits under well-watered conditions

The genotypes did not differ significantly with respect to flowering time, total water use, or water use in either the pre- or post-anthesis period. Notably, ICMH01046 had the lowest dry mass, and ICMH01031 and ICMH02044 had the highest dry mass (Table 1). Yield differed among the varieties, with ICMH02044 and ICMH01046 producing the largest and smallest yields, respectively. PRLT-2/89-33 had fewer tillers and more grains per panicle than the other genotypes. Only the NILs ICMH01031 and ICMH01046 had significantly fewer tillers than the recurrent parent H77/833-2. However, the QTL did not influence the number of grains under WW conditions (Table 1). TE was significantly lower in PRLT-2/89-33 than in most other genotypes. PRLT-2/89-33 and the recurrent parent H77/8332 had the highest and lowest 100-seed weights, respectively, while the NILs had intermediate values (Table 1).

Agronomic traits under water stress conditions

The grain yield differed significantly among the genotypes under three out of the four water stress treatments (data not shown). Overall, there was a highly significant $\mathrm{G}$ effect on yield, and the yields of H77/833-2, ICMH01031, and PRLT-2/89-33 were approximately $30 \%$ lower across all treatments than

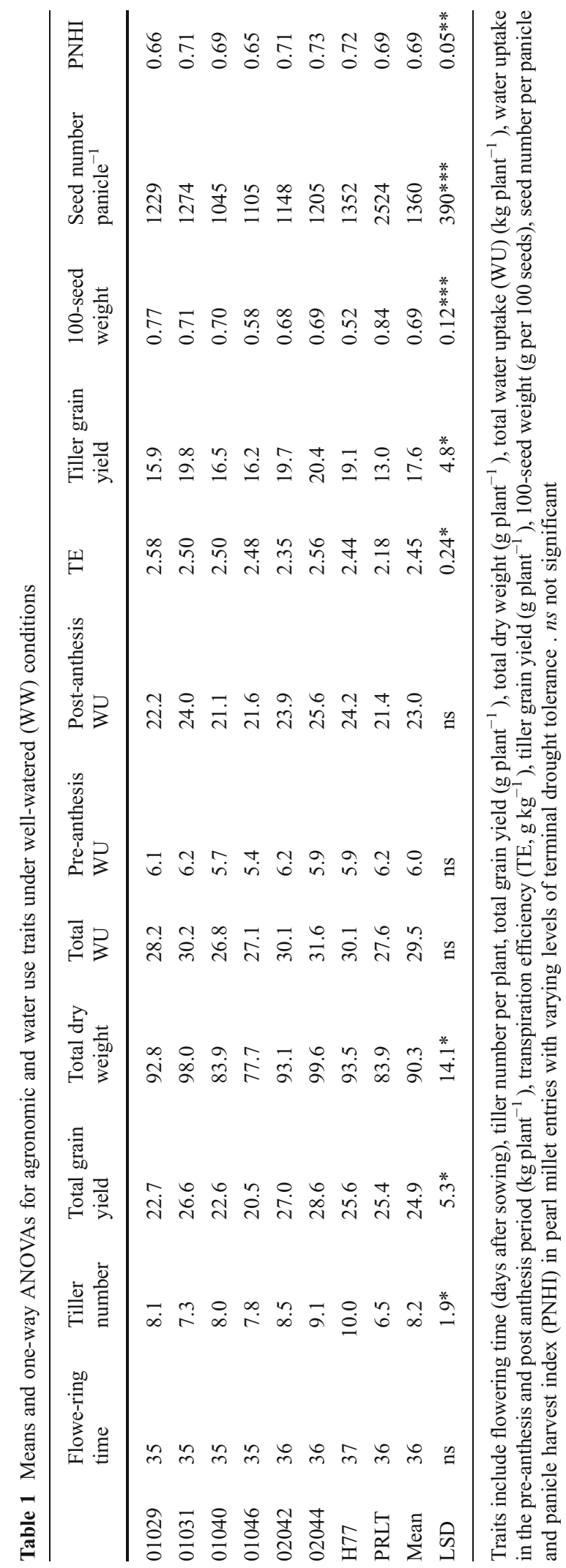


those of ICMH01029, ICMH01040, and ICMH01046 (Table 2). However, the yields of H77/833-2, ICMH01031, and PRLT-2/89-33 were up to $100 \%$ higher under specific treatments, especially in an unfilled profile (data not shown). The total dry mass differed significantly among the genotypes under the ES treatment in an unfilled profile and across all stress treatments. Differences in flowering time were small, although there were significant differences among genotypes under the LS treatment in an unfilled profile and across stress treatments in a filled profile. Differences in tiller number among genotypes were also small and were mostly related to the lower tiller number of PRLT-2/89-33 (Table 2). Genotype-bytreatment $(\mathrm{GxT})$ interaction effects were not significant for flowering time, tiller number, grain yield or total dry mass (Table 2). The yield differences between plants exposed to LS vs. ES treatments were smaller ( 10.75 vs. 9.25 g plant $^{-1}$ ) than the differences between plants grown in a full profile vs. an unfilled profile (12.0 vs. $8.0 \mathrm{~g} \mathrm{plant}^{-1}$ ), showing that the amount of water in the soil profile was a more important factor than the timing of water stress imposition.
The total water extracted from the soil profile differed significantly between the LS and ES treatments in an unfilled profile. There was also a small but significant $\mathrm{G}$ effect on water uptake across the treatments $(P<0.02)$ (Table 3$)$. However, this was mainly due to the low water uptake of the tolerant parent PRLT-2/89-33. In contrast, none of the NILs differed from the recurrent parent with respect to total water uptake, indicating that the QTL had no effect on the overall water capture of the recurrent parent (Table 3). However, pre-anthesis water use differed significantly among genotypes and across treatments, with H77/833-2 exhibiting significantly higher preanthesis water use compared with all other genotypes except ICMH01031 and ICMH02042. In contrast, the post-anthesis water uptake was significantly lower in H77/833-2 compared with ICMH01029 and ICMH01046 (Table 3). Genotypes with the highest yields exhibited lower water uptake under WS conditions before anthesis and higher water uptake compared with sensitive H77/833-2 during the postanthesis period-this was especially the case for ICMH01029 at 3 weeks after flag leaf appearance
Table 2 Flowering time (days after sowing), tiller number per plant, total grain yield ( $\mathrm{g}$ plant $\left.{ }^{-1}\right)$, and total dry mass ( $\mathrm{g}$ plant $^{-1}$ ) of eight pearl millet genotypes across all water stress treatments (Genotype) or under four water stress treatments across all genotypes (Treatment)

The water stress treatments were a combination of a late stress (LS) and early stress (ES) applied in lysimeters with either an initial full soil moisture profile (FP) or an initial unfilled soil moisture profile (UP). Some of the pearl millet genotypes contained a terminal drought tolerance QTL. Two-way ANOVA was used to determine genotype $(\mathrm{G})$, treatment $(\mathrm{T})$, and genotype-by-treatment interaction $(\mathrm{GxT})$ effects as well as least significant differences (LSDs)

\begin{tabular}{|c|c|c|c|c|}
\hline & $\begin{array}{l}\text { Flowering time } \\
\text { (days after sowing) }\end{array}$ & $\begin{array}{l}\text { Tiller number } \\
\text { plant }^{-1}\end{array}$ & $\begin{array}{l}\text { Total grain yield } \\
\left.\text { (g plant }^{-1}\right)\end{array}$ & $\begin{array}{l}\text { Total dry mass } \\
\left(\text { g plant }^{-1}\right)\end{array}$ \\
\hline \multicolumn{5}{|c|}{ Genotype } \\
\hline 01029 & 37 & 6.2 & 11.5 & 55.5 \\
\hline 01031 & 36 & 5.8 & 8.5 & 48.3 \\
\hline 01040 & 37 & 6.8 & 10.8 & 52.0 \\
\hline 01046 & 36 & 6.9 & 11.8 & 51.8 \\
\hline 02042 & 37 & 6.3 & 10.0 & 52.7 \\
\hline 02044 & 38 & 6.3 & 9.2 & 50.7 \\
\hline $\mathrm{H} 77$ & 38 & 7.5 & 8.5 & 52.8 \\
\hline PRLT & 38 & 5.2 & 8.7 & 47.7 \\
\hline LSD & 0.9 & 1.1 & 1.8 & 4.3 \\
\hline \multicolumn{5}{|c|}{ Treatment } \\
\hline LS-FP & 36 & 5.9 & 12.9 & 54.8 \\
\hline LS-UP & 35 & 5.3 & 8.5 & 49.1 \\
\hline ES-FP & 37 & 7.2 & 11.1 & 52.7 \\
\hline ES-UP & 36 & 7.2 & 7.5 & 49.7 \\
\hline \multirow[t]{2}{*}{ LSD } & 0.7 & 0.8 & 1.3 & 3.0 \\
\hline & F-Probability & F-Probability & F-Probability & F-Probability \\
\hline $\mathrm{T}$ & 0.002 & 0.001 & 0.001 & 0.001 \\
\hline G & 0.001 & 0.005 & 0.001 & 0.01 \\
\hline GxT & $\mathrm{ns}$ & $\mathrm{ns}$ & $\mathrm{ns}$ & ns \\
\hline
\end{tabular}


Table 3 Total water uptake (WU) (kg plant ${ }^{-1}$ ), transpiration efficiency (TE, in $\mathrm{g} \mathrm{kg}^{-1} \mathrm{WU}$ ), and water uptake during pre- and post- anthesis $\left(\mathrm{kg} \mathrm{plant}^{-1}\right)$ of eight pearl millet genotypes across all water stress treatments (Genotype) or under four water stress treatments across all genotypes (Treatment)
The water stress treatments were a combination of late stress (LS) and early stress (ES) applied in lysimeters with either an initial full soil moisture profile (FP) or an initial unfilled soil moisture profile (UP). The pearl millet genotypes contrasted for a terminal drought tolerance QTL. Two-way ANOVA was used to determine genotype $(\mathrm{G})$, treatment $(\mathrm{T})$, and genotype-bytreatment interaction (GxT) effects as well as least significant differences (LSDs)

$\begin{array}{llll}\begin{array}{l}\text { Total WU } \\ \left(\mathrm{kg} \mathrm{plant}^{-1}\right)\end{array} & \begin{array}{l}\text { TE } \\ \left(\mathrm{g} \mathrm{kg}^{-1} \mathrm{WU}\right)\end{array} & \begin{array}{l}\text { Pre-anthesis WU } \\ \left(\mathrm{kg} \mathrm{plant}^{-1}\right)\end{array} & \begin{array}{l}\text { Post-anthesis WU } \\ \left(\mathrm{kg} \mathrm{plant}^{-1}\right)\end{array}\end{array}$

\begin{tabular}{lllll}
\hline Genotype & & & & \\
01029 & 12.2 & 2.89 & 5.8 & 6.4 \\
01031 & 11.4 & 2.37 & 5.9 & 5.5 \\
01040 & 11.5 & 2.90 & 5.5 & 6.0 \\
01046 & 11.8 & 2.95 & 5.6 & 6.2 \\
02042 & 11.6 & 2.71 & 6.0 & 5.6 \\
02044 & 11.7 & 2.70 & 5.8 & 5.9 \\
H77 & 11.8 & 2.89 & 6.3 & 5.5 \\
PRLT & 11.2 & 2.19 & 5.4 & 5.8 \\
LSD & 0.6 & 0.35 & 0.5 & 0.7 \\
Treatment & & & & \\
LS-FP & 14.3 & 2.46 & 5.7 & 8.6 \\
LS-UP & 12.3 & 2.38 & 6.0 & 6.3 \\
ES-FP & 11.5 & 2.88 & 5.5 & 5.9 \\
ES-UP & 10.2 & 2.91 & 5.8 & 4.4 \\
LSD & 0.4 & 0.25 & 0.3 & 0.5 \\
& F-Probability & F-Probability & F-Probability & F-Probability \\
T & 0.001 & 0.001 & 0.026 & 0.001 \\
G & 0.02 & 0.001 & 0.02 & 0.04 \\
GxT & 0.05 & ns & ns & 0.05 \\
\hline
\end{tabular}

(Fig. 1a). In contrast, under fully irrigated conditions, there were no differences in the timing of water uptake except during the 2 weeks before maturity when the water uses of H77/833-2 and ICMH02042 were higher than those of ICMH01040 and ICMH01046 (Fig. 1b). Transpiration efficiency did not differ between H77/833-2 and the NILs regardless of treatment (Table 3); however, PRLT-2/89-33 had a lower TE than several of the other genotypes.

Relationships between water uptake patterns and yield components

The water uptake differences in week three after panicle emergence were regressed against the grain yield data, and a clear positive relationship emerged in both the LS (Fig. 2a) and ES treatments (Fig. 2b). These regressions revealed similar trends in water uptake at 4 weeks after sowing and post-anthesis water uptake (data not shown).

Because tillers flower later than the main culm, water uptake differences during the grain filling period might be more critical for the tillers than for the main culm. Indeed, the relationship between water uptake at 3 weeks after panicle emergence and grain yield in the tillers was highly significant $\left(\mathrm{R}^{2}=0.74\right.$; Fig. $\left.3 \mathrm{a}\right)$. There was also a significant relationship between water uptake at 3 weeks after panicle emergence and the grain yield in the main head $\left(\mathrm{R}^{2}=0.61\right.$; Fig. $\left.3 b\right)$.

These water uptake differences had notable effects on the tiller grain yields of the NILs, which were 50-100\% higher in ICMH01029, ICMH01040, and ICMH01046 compared with H77/833-2 and ICMH02044 (Table 4). The lower tiller grain yield of PRLT-2/89-33 was related to its lower tillering ability. The 100 -seed weight of the NILs also differed significantly among genotypes exposed to LS treatment in an unfilled profile, ES treatment in a filled profile, and WS treatment in all cases (data not shown). The 100-seed weight of H77/833-2 was approximately $50 \%$ lower than that of the NILs. The seed number per panicle varied significantly among genotypes: ICMH01029 and ICMH01046 had a higher seed number per panicle compared with H77/833-2 $(P<$ $0.1)$ and ICMH01031 $(P<0.05)$. ICMH01042 also had a lower seed number compared with ICMH01029 $(P<$ 0.05). Hence, the panicle harvest index (PNHI) of 
Fig. 1 Pattern of water extraction from the time of panicle emergence until maturity in six pearl millet germplasm entries including the recurrent parent $\mathrm{H} 77 / 833$ 2 and lines introgressed with a terminal drought tolerance QTL from the donor (PRLT2) 89-33) into the background of recurrent parent. Water uptake $\left(\mathrm{kg}_{\text {plant }}{ }^{-1}\right.$ week $\left.^{-1}\right)$ was measured under water stress (WS, a) and well watered (WW, b) conditions. Vertical bars indicate LSD at $P<0.05$. The absence of bars above specific dates indicates that genotypic differences were not significant. The timing of intervals indicates the number of weeks after panicle emergence, and the water uptake data assigned to each date corresponds to the time period (usually 1 week) preceding that date. The data are the means of 20 lysimeters exposed to early water stress and late water stress and include cylinders with filled and un-filled profiles
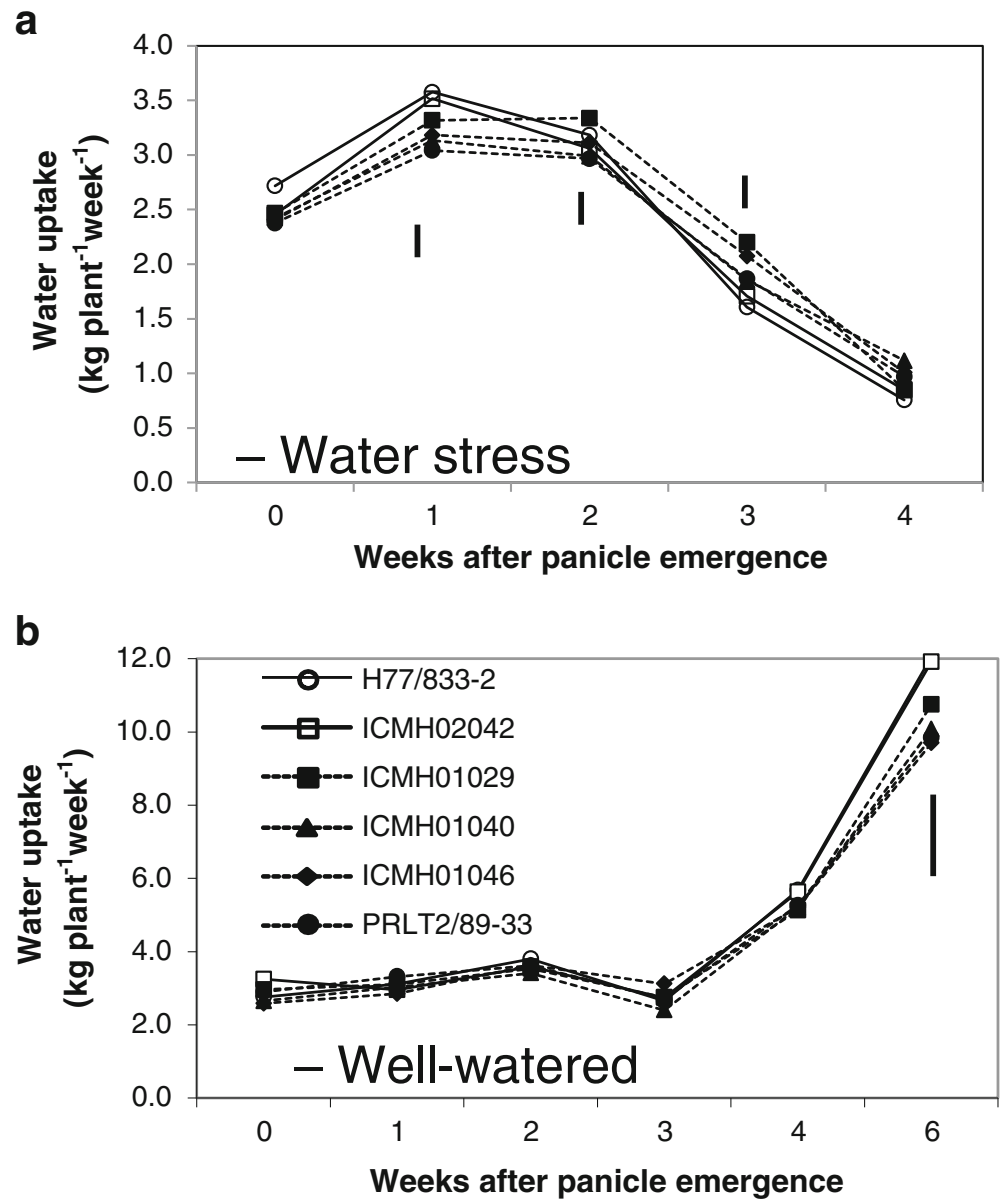

ICMH01029, ICMH01040, and ICMH01046 was higher than that of $\mathrm{H} 77 / 833-2$ across all water stress treatments (Table 4).

Relationships between water uptake and staygreen score

Staygreen scores were recorded for plants exposed to LS treatment, and these scores were tightly correlated with water uptake during week three after panicle emergence in both filled $\left(\mathrm{R}^{2}=0.79\right)$ and unfilled profiles $\left(\mathrm{R}^{2}=0.76\right)$ (excluding values for PRLT-2/89-33 on the right side of the regression) (Fig. 4).

Interactions between yield, water use, transpiration efficiency and harvest index

A multi-linear additive model indicated a predominant role for the harvest index $(\mathrm{HI})$ under all watering regimes (Table 5). Under WW conditions, the magnitude of the HI effect was slightly above that of the water uptake (WU) effect, whereas under the LS and ES treatments, HI had the most prominent effect.

Other multi-linear regressions were performed in which water uptake amounts during each of the weeks after panicle emergence were included in the additive model. Under WW conditions, the temporal water uptake pattern did not significantly affect the total water use coefficient (data not shown). In contrast, under the late stress treatment, the magnitude of the total water use coefficient was small compared with the TE and HI coefficients (Table 6). In agreement with the results reported above (Fig. 1-Suppl Fig. 1), the amount of water uptake in weeks three and four after panicle emergence had a strong effect on yield that was similar in magnitude to the effect of total water use. Similar results were obtained with the early stress treatment (data not shown). The effects of temporal patterns of water use on the panicle harvest index (PNHI) were tested in the late stress treatment, 
Fig. 2 Relationships between the total grain yield at maturity and the water extracted ( $\mathrm{kg} \mathrm{plant}^{-1}$ ) during the third week after panicle emergence under late stress (LS, a, open and closed circles) and early stress (ES, b, open and closed squares) conditions. Lysimeters with an initial full soil profile are represented by closed symbols, while those with an initial unfilled profile are represented by open symbols
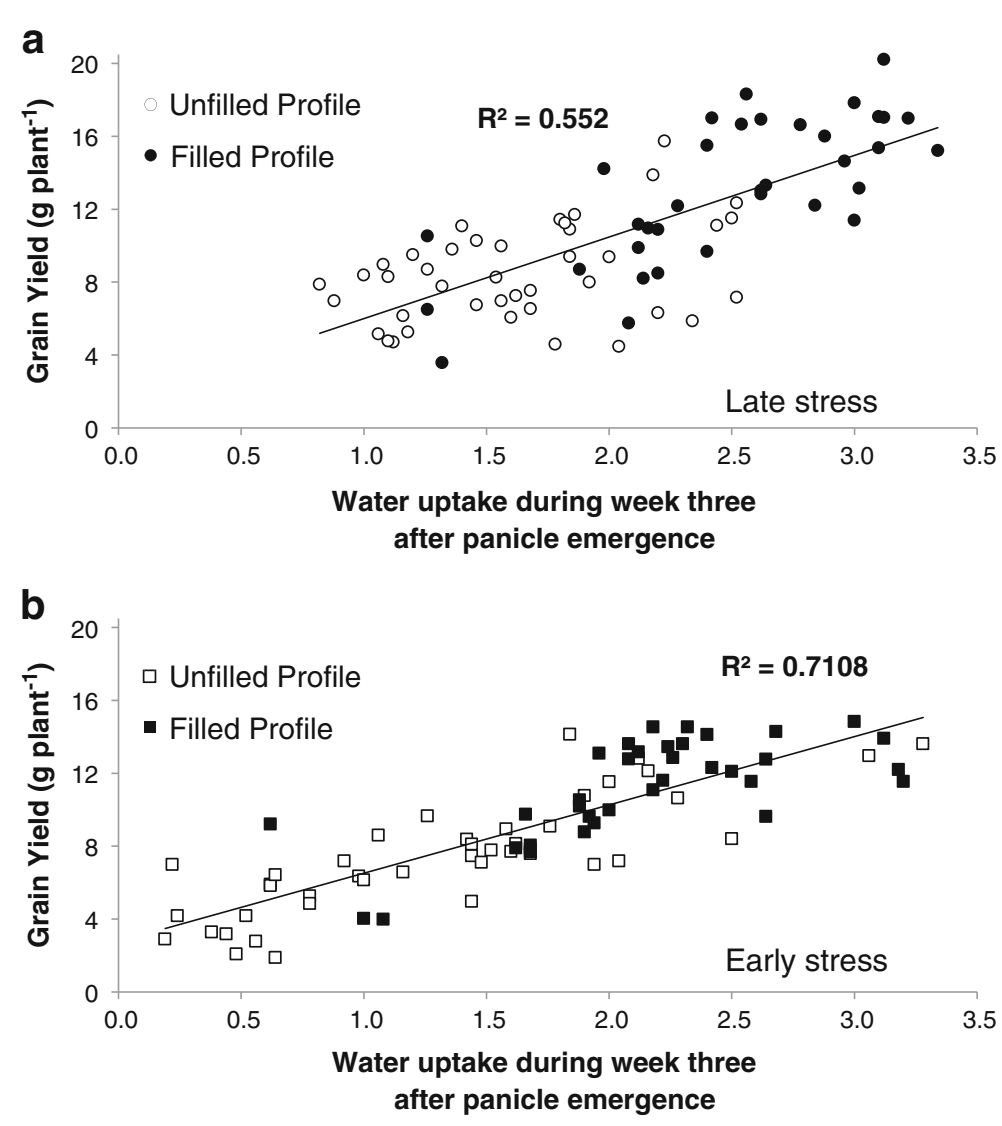

and it was found that water uptake had a very strong negative effect on PNHI in week two after panicle emergence. However, water uptake had very strong positive effects on PNHI in weeks three and four after panicle emergence. Similar results were obtained with the early stress treatment (data not shown). Additionally, similar coefficient values were obtained when the harvest index was used as a dependent variable in place of PNHI (data not shown), indicating strong interactions between the coefficients of the water-based framework (WU, TE and HI).

\section{Discussion}

This work showed yield differences under terminal stress conditions and a lack of yield differences under well-watered conditions in the lysimetric system. This confirmed the results obtained with these genotypes in earlier field trials (Serraj et al. 2005) and therefore validated the use of the lysimetric platform for obtaining relevant agronomic assessments under controlled conditions. The highest yielding genotypes under terminal drought stress did not extract more water from the soil profile but rather exhibited a pattern of water extraction that favoured increased water uptake during the post-anthesis period and less water uptake around and before anthesis. Higher water uptake at 3 and 4 weeks after panicle emergence then led to higher grain yields, especially under the early stress treatment, and enhanced tiller yield slightly more than the main head yield. A very important result obtained during this study was that the increased water extraction at 3 weeks after panicle emergence was significantly correlated with higher staygreen scores, which can be recorded in the field and used as a simple proxy for measurement of water extraction during grain filling under terminal drought.

Yield and evaluation of Passioura's equation components in the lysimetric system

The results presented here provide confirmation that lysimeters are suitable for obtaining relevant agronomic assessments under various environmental conditions. 
Fig. 3 Relationships between the grain yield of the tillers (a) and the main head (b) and the water extracted (kg plant ${ }^{-1}$ ) during the third week after panicle emergence in the late stress (triangle) and early stress (square) conditions. Lysimeters with an initial full soil profile are indicated by closed symbols, while those with an initial unfilled profile are represented by open symbols. The data are the means of five replicate plants per genotype and water treatment combination. The large circles (open and closed representing unfilled and filled profiles, respectively) represent the data points for PRLT2-98/33, a low-tillering line that was excluded from the regression analysis involving tiller grain yield a

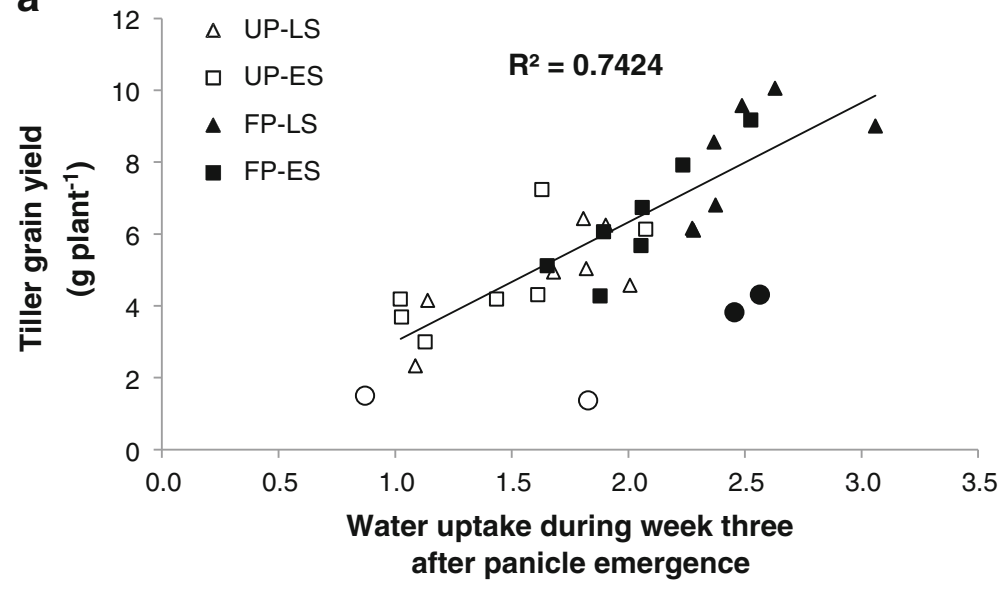

b

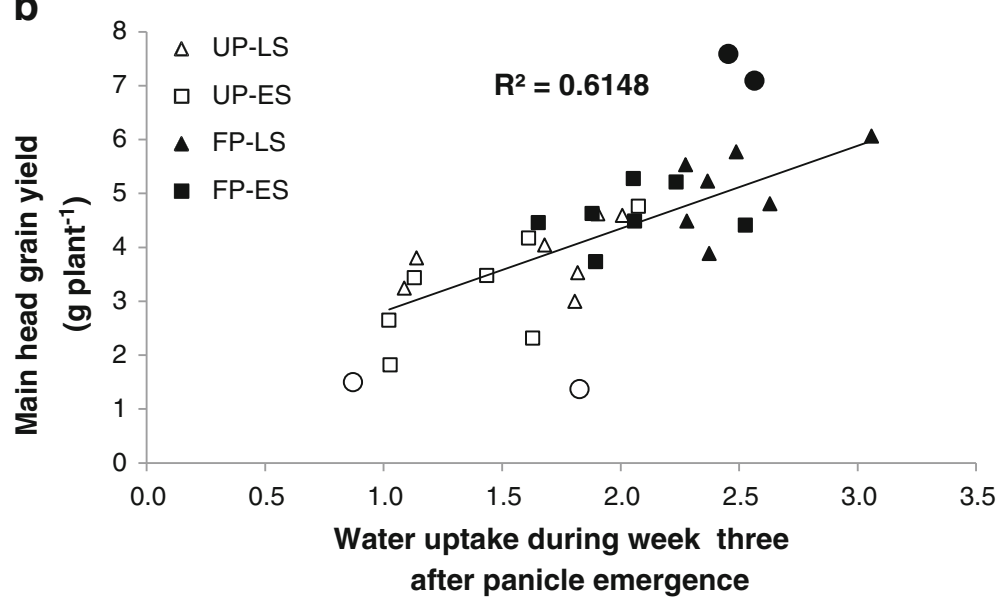

This is important because the system was used here to assess possible relationships between temporal patterns of water use and yield. These results confirm other recent assessments using this system. For example, in a trial examining twenty chickpea genotypes that were selected based on their highly divergent phenotypes under terminal drought stress during 3 years of field assessments (Krishnamurthy et al. 2010), eleven out of twelve tolerant lines were also tolerant in the lysimeters, and seven out of eight sensitive lines were also sensitive in the lysimeters (Zaman-Allah et al. 2011a). Similar results were obtained in peanut (Ratnakumar and Vadez 2011) and sorghum (Vadez et al. 2011b). The reason for the similarity between lysimetric and field assessments is partially due to the similarity in plant spacing, soil availability for water exploration, and general growing conditions as the lysimetric facility is outdoors. Of course, plants are grown individually in the tubes, and the system cannot mimic potential root-to-root competition. Therefore, this system provides an opportunity to measure yield and other components and relate these to in vivo assessments of water uptake and phenotypes that are normally measured in the field.

The system also allows for the assessment of TE over the long term; therefore, comparisons can be made to previous studies in which long-term assessments were performed. For example, TEs in Payne et al. (1992) were approximately 5 and $8 \mathrm{~g} \mathrm{~kg}^{-1}$ under WW and WS conditions, respectively (approximately 600 and $200 \mathrm{~g}$ of biomass transpired approximately 120 and $25 \mathrm{~kg}$ of water under WW and WS conditions, respectively). Using Bierhuizen and Slatyer's equation (1965), which is akin to TE=k/VPD, ' $k$ ' coefficient values of 7.5 and $12 \mathrm{~Pa}$ under WW and WS were estimated from Payne's experiment using $1.5 \mathrm{kPa}$ as the average VPD. In comparison, the mean TE in our experiment were 2.45 and 2.70 under $\mathrm{WW}$ and $\mathrm{WS}$, respectively, yielding ' $\mathrm{k}$ ' values of 6.1 and $6.7 \mathrm{~Pa}$ 
Table 4 Tiller grain yield $\left(\mathrm{g}\right.$ plant ${ }^{-1}$ ), 100-seed weight (g per 100 seeds), seed number per panicle and panicle harvest index (PNHI) of eight pearl millet genotypes across all water stress treatments (Genotype) or under four water stress treatments across all genotypes (Treatment)

Tiller grain yield $\left(\mathrm{g} \mathrm{plant}^{-1}\right) \quad 100$-seed weight $(\mathrm{g})$

Grain number panicle ${ }^{-1}$

Panicle harvest index (PNHI)

\begin{tabular}{lllll}
\hline Genotype & & & & \\
01029 & 6.8 & 0.43 & 989 & 0.51 \\
01031 & 5.1 & 0.45 & 692 & 0.44 \\
01040 & 6.7 & 0.48 & 790 & 0.52 \\
01046 & 8.0 & 0.51 & 937 & 0.53 \\
02042 & 5.8 & 0.40 & 731 & 0.48 \\
02044 & 4.8 & 0.38 & 788 & 0.47 \\
H77 & 4.2 & 0.31 & 782 & 0.44 \\
PRLT & 2.7 & 0.48 & 1387 & 0.48 \\
LSD & 1.4 & 0.08 & 221 & 0.06 \\
Treatment & & & & 0.55 \\
LS-FP & 7.6 & 0.49 & 960 & 0.44 \\
LS-UP & 4.4 & 0.40 & 794 & 0.53 \\
ES-FP & 6.1 & 0.49 & 941 & 0.43 \\
ES-UP & 4.3 & 0.35 & 864 & 0.04 \\
LSD & 1.0 & 0.05 & - & F-Probability \\
T & F-Probability & F-Probability & F-Probability & 0.001 \\
G & 0.001 & 0.001 & ns & 0.007 \\
GxT & ns & 0.001 & 0.001 & ns
\end{tabular}

The water stress treatments were a combination of late stress (LS) and early stress (ES) applied in lysimeters with either an initial full soil moisture profile (FP) or an initial unfilled soil moisture profile (UP). The pearl millet genotypes contrasted for a terminal drought tolerance QTL. Two-way ANOVA was used to determine genotype (G), treatment (T), and genotype-by-treatment interaction (GxT) effects as well as least significant differences (LSDs)

under WW and WS, respectively. The slightly lower values in our experiment are related to the omission of roots from the biomass calculation; in contrast, roots were included in Payne's experiment and accounted for approximately one third of the biomass. The larger differences in the coefficients under WS could be related to differences in the VPD during WS and indicate that future studies should include distinct VPD assessments for each treatment. Regardless of this, the lysimetric approach provided a more precise assessment of plant water use than experiments performed in the field where transpiration was inferred from neutron probe data (Azam-Ali et al. 1984). A key finding was that the QTL introgression lines did not vary with respect to total water extraction. It must be noted that individual plant evaluations in the lysimetric system are no substitute for field data, which provide a "real" assessment of plant populations.

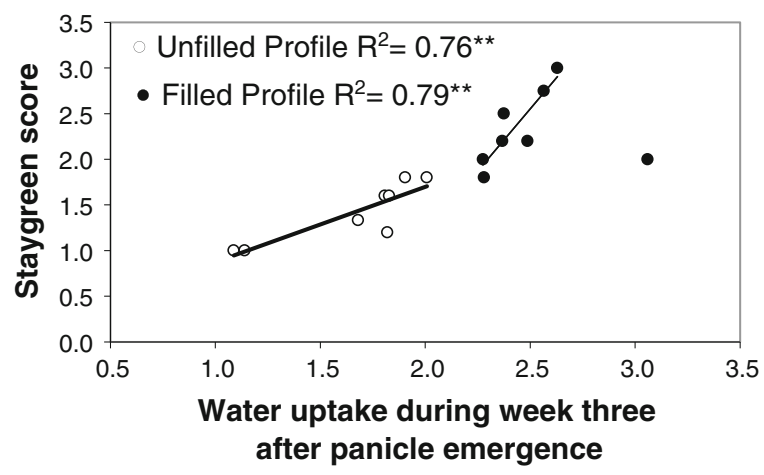

Fig. 4 Relationships between the staygreen scores (1, most of the leaves are wilted and senescing; 2, approximately half of the leaves are wilted and senescing; 3 , almost all the leaves are green and turgid) and the water extracted ( $\mathrm{kg} \mathrm{plant}^{-1}$ ) during the third week after panicle emergence under the late stress treatment. Lysimeters with an initial full soil profile are represented by closed symbols while those with an initial unfilled profile are represented by open symbols. The data point obtained from the filled lysimeter on the right hand side of the graph was excluded from the regression analysis 
Table 5 Multi-linear additive model regressions between the total grain yield and the total water uptake (WU), transpiration efficiency (TE), and harvest index (HI) under the well-watered (WW), late stress (LS), and early stress (ES) treatments
' $\mathrm{t}$ ' and $\mathrm{P}>\mathrm{t}$ are the coefficient and the probability that the parameter exerts a significant effect on the dependent variable, respectively

\begin{tabular}{lclrl}
\hline & Coefficient & Standard error & $\mathrm{t}$ & $\mathrm{P}>\mathrm{t}$ \\
\hline Grain yield - WW & $\left(\mathrm{R}^{2}=0.98\right)$ & & & \\
WU & 0.00094 & 0.00002 & 42.6 & 0.001 \\
TE & 9.34 & 0.33 & 27.9 & 0.001 \\
HI & 98.9 & 1.8 & 55.2 & 0.001 \\
Constant & -58.8 & 1.3 & -44.7 & 0.001 \\
Grain yield - LS $\left(\mathrm{R}^{2}=0.98\right)$ & & & \\
WU & 0.00074 & 0.00003 & 23.7 & 0.001 \\
TE & 2.69 & 0.09 & 29.9 & 0.001 \\
HI & 53.3 & 0.7 & 72.1 & 0.001 \\
Constant & -20.7 & 0.6 & -32.5 & 0.001 \\
Grain yield - ES $\left(\mathrm{R}^{2}=0.99\right)$ & & & \\
WU & 0.00079 & 0.00003 & 26.5 & 0.001 \\
TE & 1.58 & 0.08 & 19.7 & 0.001 \\
HI & 50.4 & 0.7 & 74.0 & 0.001 \\
Constant & -15.4 & 0.6 & -28.4 & 0.001 \\
\hline
\end{tabular}

In summary, the lysimetric system proved to be a critical tool for obtaining accurate assessments of the

Table 6 Upper section: multi-linear regression between the total grain yield under the late stress treatment and the following explanatory variables: total water uptake (WU), transpiration different components of the Passioura equation while also allowing for highly relevant agronomic assessments.

efficiency (TE), harvest index (HI), and water uptake at weeks $0,1,2,3$, and 4 after panicle initiation (WU-Wk0, WU-Wk1, WU-Wk2, WU-Wk3, WU-Wk4)

\begin{tabular}{|c|c|c|c|c|}
\hline & Coefficient & Standard error & $\mathrm{t}$ & $\mathrm{P}>\mathrm{t}$ \\
\hline \multicolumn{5}{|c|}{ Grain yield $\left(\mathrm{R}^{2}=0.98\right)$} \\
\hline WU & 0.00041 & 0.00009 & 4.7 & 0.001 \\
\hline $\mathrm{TE}$ & 2.57 & 0.09 & 28.6 & 0.001 \\
\hline HI & 51.6 & 1.0 & 52.1 & 0.001 \\
\hline WU-Wk0 & 0.00047 & 0.00012 & 4.03 & 0.001 \\
\hline WU-Wk1 & 0.00017 & 0.00008 & 2.01 & 0.05 \\
\hline WU-Wk2 & 0.00015 & 0.00013 & 1.19 & Ns \\
\hline WU-Wk3 & 0.00036 & 0.00017 & 2.16 & 0.03 \\
\hline WU-Wk4 & 0.00060 & 0.00013 & 4.63 & 0.001 \\
\hline Constant & -19.2 & 0.7 & -25.87 & 0.001 \\
\hline \multicolumn{5}{|c|}{ Panicle harvest index $\left(\mathrm{R}^{2}=0.53\right)$} \\
\hline WU-Wk0 & 0.000011 & 0.000011 & 0.98 & Ns \\
\hline WU-Wk1 & $2.810-6$ & $9.010-6$ & 0.31 & Ns \\
\hline WU-Wk2 & -0.000100 & 0.000014 & -7.31 & 0.001 \\
\hline WU-Wk3 & 0.000063 & 0.000016 & 3.87 & 0.001 \\
\hline WU-Wk4 & 0.000055 & 0.000013 & 4.36 & 0.001 \\
\hline Constant & 0.61 & 0.07 & 8.74 & 0.001 \\
\hline
\end{tabular}

Lower section: multi-linear regression between the panicle harvest index (PNHI, i.e., the ratio of total grain weight to total panicle weight) under the late stress treatment and water uptake at weeks $0,1,2,3$, and 4 after panicle emergence. ' $t$ ' and $P>t$ are the coefficient and the probability that the parameter exerts a significant effect on the dependent variable, respectively

ns non-significant 
Differences in water uptake patterns are critical for achieving higher yields under drought conditions

In these experiments, HI was most closely associated with yield under LS and ES treatments. Aside from $\mathrm{HI}$, total water extraction had a direct and significant effect on yield, although this effect was much stronger under ES compared with LS treatment $\left(\mathrm{R}^{2}=0.12\right.$ under LS treatment and $\mathrm{R}^{2}=0.48$ under ES treatment). This was also reflected by the high magnitude of the WU component under LS and ES treatments in the multi-linear analysis (Table 5). However, the high magnitude of the WU component was mainly related to higher water uptake in weeks three and four after panicle emergence (Fig. 2), which indicated the relative importance of temporal patterns of water use vs. total water uptake. The slopes of the regressions between grain yield and water extracted (LS, Fig. 2a; ES, Fig. 2b) were $4.5 \mathrm{~g} \mathrm{~kg}^{-1}$ and $3.7 \mathrm{~g} \mathrm{~kg}^{-1}$ for LS and ES, respectively, which can be extrapolated to $45 \mathrm{~g} \mathrm{~mm}^{-1}$ and $37 \mathrm{~g} \mathrm{~mm}^{-1}$ water at the sowing density used in our experiments $\left(10\right.$ plants $\left.\mathrm{m}^{-2}\right)$. These values are close to those previously reported for wheat: each millimetre of water extracted during grain filling led to a yield increase of $55 \mathrm{~kg} \mathrm{ha}^{-1}$ (Manschadi et al. 2006) or 59 $\mathrm{kg} \mathrm{ha}^{-1}$ (Kirkegaard et al. 2007). Additionally, the multi-linear analysis showed that the panicle harvest index was negatively related to water uptake early in the cycle and positively related to water uptake late in the cycle (Table 6), indicating that strong interactions occur between the components of the Passioura equation, and as suggested in previous reports, these interactions require close temporal scrutiny while using this water-based framework (Condon and Richards 1993).

An important finding was that higher water extraction in week three after panicle emergence was also closely related to staygreen score. It is interesting that among the main mechanistic hypotheses proposed thus far to explain the expression of staygreen, most have been related to plant nitrogen status (e.g., Borrell et al. 2001; Thomas and Howarth 2000) while only a few have been related to water status (Tuinstra et al. 1998). However, several reports have shown that staygreen was likely to be associated with the maintenance of root growth (Hatlitligil et al. 1984; MacKay and Barber 1986), which could be another means of making water available. Therefore, the expression of staygreen is related to the maintenance of water uptake. Scoring of the staygreen phenotype then offers a simple proxy for measuring water uptake differences in the field and is now used to phenotype pearl millet genotypes under terminal drought conditions. Of course, other confounding factors such as the genotype, the size of the panicle, or the number of grains could also affect the staygreen score. The increased water extraction late in the grain filling period benefitted the tillers more than the main head. The quality and precision of yield data could be improved by measuring tiller yield rather than total grain yield. This has also some important implications because germplasms vary with respect to the rate at which tillers flower. Intuitively, genotypes in which the tillers flower soon after the main head would have an advantage over genotypes in which these tillers flower later with respect to their level of terminal drought stress tolerance. In summary, the lysimetric system proved to be a critical tool for elucidating the mechanisms of terminal drought adaptation by illustrating the critical importance of increased water extraction during grain filling while also allowing for a highly relevant agronomic evaluation and providing effective scoring systems (e.g., staygreen scores) for breeding programs.

These results, which illustrate the importance of temporal water use patterns, are in close agreement with earlier results indicating that terminal droughttolerant chickpea genotypes also exhibited increased water extraction during the grain filling period (Zaman-Allah et al. 2011a). In fact, converging evidence from different crops indicates that "shifting" water use from the vegetative to the reproductive stage may increase yield under water-limited conditions, and there are several different ways to achieve this. Lower canopy conductance and transpiration sensitivity to a high vapour pressure deficit were reported previously in pearl millet germplasm entries that achieved high yields under drought conditions (Kholová et al. 2010a, b). Therefore, lower water use around and before anthesis is likely to be related to water conservation traits operating at the vegetative stage in the tolerant genotypes. Similar results were previously reported in chickpea and cowpea, where lower canopy conductance and decreased vegetative biomass at the vegetative stage, both of which contribute to water conservation, were used to distinguish tolerant from sensitive genotypes in a series of pot experiments (Zaman-Allah et al. 2011b; Belko et al. 2012) and altered the pattern of water uptake, leading 
to seed yield differences in the lysimeters (ZamanAllah et al. 2011a). Previous work in wheat also uncovered genotypes with a decreased rate of water use (e.g., Condon et al. 2004) or a small plant size (e.g., Fischer and Wood 1979), which are adaptations to conditions in which the crop depends mostly on stored soil moisture (e.g., Condon et al. 2004). ICMH01046, which had a decreased biomass under WW conditions, is similar to these examples, and it also exhibited reduced tillering under WW conditions. The reduction in tillering also contributes to a decrease in plant size and agrees with a recent report indicating that under certain planting densities and moderate temperature conditions, a faster leaf appearance rate could increase the vigour of the main culm and lead to reduced tillering in sorghum, which would then result in a decrease in leaf area at anthesis and less water use before anthesis (van Oosterom et al. 2011). Therefore, in various crops, adaptation to end-of-season drought is associated with water conservation traits during preanthesis including lower canopy conductance and/or small plant size. The exact mechanism by which small plant size is achieved may vary; however, tillering seems to play a role in this mechanism.

Water uptake differences between genotypes at 3 and 4 weeks after panicle emergence accounted for a maximum of 1.0-1.5 $\mathrm{L} \mathrm{plant}^{-1}$. Because the planting density in the lysimeters was approximately 10 plants $\mathrm{m}^{-2}$, these water uptake differences corresponded to approximately $10-15 \mathrm{~mm}$. This is small but critical, as previously shown in wheat (Manschadi et al. 2006). In fact, similar findings were obtained in chickpeas that were tolerant to terminal drought; in these plants, differences in temporal patterns of water uptake were estimated to be approximately $25 \mathrm{~mm}$ (Zaman-Allah et al. 2011a). In contrast, the lack of significant differences in total water uptake between H77/833-2 and the tolerant introgression lines indicates that the terminal drought tolerance QTL was not likely to have an effect on the water extraction capacity of the root system. Although this could have been caused by a constraint on root development, this possibility is unlikely because earlier work in sorghum (Vadez et al. 2011a, b) reported a water extraction of over $15 \mathrm{~L}$ in the same tubes and a pearl millet germplasm extracted over $13 \mathrm{~L}$ (unpublished). This reemphasises the importance of temporal patterns of water use for increasing grain yield under terminal drought stress. It appears that these characteristics are shared among crops that face similar constraints. Therefore, the current study showed that yield increases cannot be accomplished by simply maximising plant water extraction (earlier referred to as "efficient use of water, EUW", Blum 2009). Here, the total amount of water extracted by all genotypes was similar, and yield differences arose when this limited water resource was managed in a way that maximised post-anthesis water use. Thus, the concept of "efficient water use" requires some consideration of the dynamics of water use.

\section{Conclusion}

Temporal patterns of water use, rather than total water extraction, were essential for explaining the terminal drought tolerance of pearl millet genotypes containing a terminal drought tolerance QTL. Therefore, the terminal drought QTL did not affect the water extraction capacity of the root system. Increased water uptake during the post anthesis period led to a higher yield, especially with respect to tillers, and also led to the expression of a staygreen phenotype. The differential patterns of water uptake were thought to be consequences of the water saving traits reported earlier. The lysimetric setup was able to provide a highly relevant agronomic assessment, and its capacity to achieve a direct, precise and dynamic measurement of the components of a water-based framework $(\mathrm{Y}=\mathrm{WU} \times \mathrm{TE} \times$ $\mathrm{HI})$ revealed the high level of interactions between these components.

Acknowledgments The senior author was partially supported by a grant from DFIDBBSRC (Research Contract BB/F004133/ 1). The authors wish to thank Mr M. Anjaiah and N. Pentaiah for their expert technical support. The lysimetric facility was established thanks to a grant from the Department of Biotechnology (DBT), Government of India, to ICRISAT's Center of Excellence in Genomics.

Open Access This article is distributed under the terms of the Creative Commons Attribution License which permits any use, distribution, and reproduction in any medium, provided the original author(s) and the source are credited.

\section{References}

Azam-Ali SN, Gregory PJ, Monteith JL (1984) Effects of planting density on water use and productivity of pearl millet (Pennisetum typhoides) grown on stored water: II. Water use, light interception and dry matter production. Exp Agric 20:215-224 
Belko N, Zaman-Allah M, Diop NN, Cisse N, Ehlers JD, Ndoye O, Zombre G, Vadez V (2012) Lower soil moisture threshold for transpiration decline under water deficit correlates with lower canopy conductance and higher transpiration efficiency in drought tolerant cowpea. Funct Plant Biol. doi:10.1071/FP11282

Bidinger FR, Mahalakshmi V, Rao GDP (1987) Assessment of drought resistance in pearl millet [Pennisetum americanm (L.) Leeke]. II estimation of genotype response to stress. Aust J Agric Res 38:49-59

Bierhuizen JF, Slatyer (1965) Effect of atmospheric concentration of water vapor and $\mathrm{CO}_{2}$ in determining transpirationphotosynthesis relationships of cotton leaves. Agric Meteorol 2:259-270

Blum A (2009) Effective use of water (EUW) and not water-use efficiency (WUE) is the target of crop yield improvement under drought stress. Field Crop Res 112:119-123

Borrell A, Hammer G, van Oosterom E (2001) Stay-green: a consequence of the balance between supply and demand for nitrogen during grain filling. Ann Appl Biol 138:91-95

Cattivelli L, Rizza F, Badeck F-W, Mazzucotelli E, Mastrangelo AM, Francia E, Mare C, Tondelli A, Stanca AM (2008) Drought tolerance improvement in crop plants: an integrated view from breeding to genomics. Field Crop Res 105:1-14

Condon AG, Richards RA (1993) Exploiting genetic variation in transpiration efficiency in wheat: an agronomic view. In: Ehleringer JR, Hall AE, Farquhar GD (eds) Stable isotopes and plant carbonwater relations. Academic, San Diego, pp 435-450

Condon AG, Richards RA, Rebetzke GJ, Farquhar GD (2002) Improving intrinsic water-use efficiency and crop yield. Crop Sci 42:122-131

Condon AG, Richards RA, Rebetzke GJ, Farquhar GD (2004) Breeding for high water use efficiency. J Exp Bot 55:24472460

Ehdaie B, Layne AP, Giles WJ (2012) Root system plasticity to drought influences grain yield in bread wheat. Euphytica 186:219-232

Fischer RA, Wood JT (1979) Drought resistance in spring wheat cultivars. III. Yield association with morpho-physiological traits. Aust J Agric Res 30:1001-1020

Gaur PM, Krishnamurthy L, Kashiwagi J (2008) Improving drought-avoidance root traits in chickpea (Cicer arietinum L.) - current status of research at ICRISAT. Plant Prod Sci 11:3-11

Hatlitligil MB, Olson RA, Compton WA (1984) Yield, water use, and nutrient uptake of corn hybrids under varied irrigation and nitrogen regimes. Fert Res 5:321-333

Hund A, Ruta N, Liedgens M (2009) Rooting depth and water use efficiency of tropical maize inbred lines, differing in drought tolerance. Plant Soil 318:311-325

Kano M, Inukai Y, Kitano H, Yamauchi A (2011) Root plasticity as the key root trait for adaptation to various intensities of drought stress in rice. Plant Soil 342:117-128

Kashiwagi J, Krishnamurthy L, Crouch JH, Serraj R (2006) Variability of root characteristics and their contributions to seed yield in chickpea (Cicer arietinum L) under terminal drought stress. Field Crop Res 95:171-181

Kholová J, Hash CT, Kumar LK, Yadav RS, Kocŏvá M, Vadez $\mathrm{V}$ (2010a) Terminal drought tolerant pearl millet [Pennisetum glaucum (L.) R. Br.] have high leaf ABA and limit transpiration at high vapor pressure deficit. J Exp Bot 61:1431-1440

Kholová J, Hash CT, Kocŏvá M, Vadez V (2010b) Constitutive water conserving mechanisms are correlated with the terminal drought tolerance of pearl millet (Pennisetum americanum L.). J Exp Bot 61:369-377

Kirkegaard JA, Lilley JM, Howe GN, Graham JM (2007) Impact of subsoil water use on wheat yield. Aust J Agric Res 58:303-315

Krishnamurthy L, Kashiwagi J, Gaur PM, Upadhyaya HD, Vadez V (2010) Sources of tolerance to terminal drought in the chickpea (Cicer arietinum L.) minicore germplasm. Field Crop Res 119:322-330

MacKay AD, Barber SA (1986) Effect of nitrogen on root growth of two genotypes in the field. Agron J 78:699-703

Manschadi AM, Christopher JT, Peter deVoil P, Hammer GL (2006) The role of root architectural traits in adaptation of wheat to water-limited environments. Funct Plant Biol 33:823-837

Manshadi AM, Christopher JT, Hammer GL, Devoil P (2010) Experimental and modelling studies of drought-adaptive root architectural traits in wheat (Triticum aestivum L.). Plant Biosyst 144:458-462

Mori M, Inagaki MN (2012) Root development and wateruptake under water deficit stress in drought-adaptive wheat genotypes. Cereal Res Commun 40:44-52

Passioura JB (1977) Grain yield, harvest index and water use of wheat. J Aust Inst Agric Sci 43:117-121

Payne WA, Lascano RJ, Hossner LR, Wendt CW, Onken AB (1991) Pearl millet growth as affected by phosphorus and water. Agron J 83:942-948

Payne WA, Drew MC, Hossner LR, Lascano RJ, Onken AB, Wendt CW (1992) Soil phosphorus availability and pearl millet water use efficiency. Crop Sci 32:1010-1015

Price AH, Tomos AD (1997) Genetic dissection of root growth in rice (Oryza sativa L.). II. Mapping quantitative trait loci using molecular markers. Theor Appl Genet 95:143-152

Ratnakumar P, Vadez V (2011) Groundnut (Arachis hypogaea L.) genotypes tolerant to intermittent drought maintain a high harvest index and have small leaf canopy under stress. Funct Plant Biol. doi:10.1071/FP11145

Rebetzke GJ, Condon AG, Richards RA, Farquhar GD (2002) Selection for reduced carbon-isotope discrimination increases aerial biomass and grain yield of rainfed bread wheat. Crop Sci 42:739-745

Serraj R, Hash CT, Rizvi SMH, Sharma A, Yadav RS, Bidinger FR (2005) Recent advances in marker-assisted selection for drought tolerance in pearl millet. Plant Prod Sci 8:334-337

Thomas H, Howarth CJ (2000) Five ways to stay green. J Exp Bot 51:329-337

Tuberosa R, Sanguineti MC, Landi P, Giuliani MM, Salvi S, Conti S (2002) Identification of QTLs for root characteristics in maize grown in hydroponics and analysis of their overlap with QTLs for grain yield in the field at two water regimes. Plant Mol Biol 48:697-712

Tuinstra MR, Ejeta G, Goldsbrough P (1998) Evaluation of near isogenic sorghum lines contrasting for QTL markers associated with drought tolerance. Crop Sci 38:835-842

Vadez V, Krishnamurthy L, Kashiwagi JW, Kholová J, Devi JM, Sharma KK, Bhatnagar-Mathur P, Hoisington DA, Hash CT, Bidinger FR, Keatinge JDH (2007) Exploiting the 
functionality of root systems for dry, saline, and nutrient deficient environments in a changing climate. J SAT Agric Res 4 (Special Symposium edition) http://www.icrisat.org/ journal/specialproject.htm

Vadez V, Rao S, Kholová J, Krishnamurthy L, Kashiwagi J, Ratnakumar P, Sharma KK, Bhatnagar-Mathur P, Basu PS (2008) Roots research for legume tolerance to drought: Quo vadis? J Food Leg 21:77-85

Vadez V, Krishnamurthy L, Hash CT, Upadhyaya HD, Borrell AK (2011a) Yield, transpiration efficiency, and water use variations and their relationships in the sorghum reference collection. Crop Pasture Sci 62:1-11

Vadez V, Deshpande SP, Kholová J, Hammer GL, Borrell AK, Talwar HS, Hash CT (2011b) Staygreen QTL effects on water extraction and transpiration efficiency in a lysimetric system: influence of genetic background. Funct Plant Biol 38:553-566

Van Oosterom EJ, Borrell AK, Deifel KS, Hammer GL (2011) Does increased leaf appearance rate enhance adaptation to postanthesis drought stress in sorghum? Crop Sci 51:27282740

Yadav RS, Hash CT, Bidinger FR, Cavan GP, Howart CJ (2002) Quantitative trait loci associated with traits determining grain and stover yield in pearl millet under terminad drought-stress conditions. Theor Appl Genet 104:67-83

Yadav RS, Hash CT, Bidinger FR, Devos KM, Howarth CJ (2004) Genomic regions associated with grain yield and aspects of post-flowering drought tolerance in pearl millet across stress environments and testers background. Euphytica 136:265-277

Zaman-Allah M, Jenkinson D, Vadez V (2011a) Chickpea genotypes contrasting for seed yield under terminal drought stress in the field differ for traits related to the control of water use. Funct Plant Biol 38:270-281

Zaman-Allah M, Jenkinson D, Vadez V (2011b) A conservative pattern of water use, rather than deep or profuse rooting, is critical for the terminal drought tolerance of chickpea. J Exp Bot 62:4239-4252 